\title{
SYMBIOSES BETWEEN INSECTS AND SPIDERS: AN ASSOCIATION BETWEEN LEPIDOPTERAN LARVAE AND THE SOCIAL SPIDER ANELOSIMUS EXIMIUS (ARANEAE: THERIDIIDAE)*
}

\author{
By Michael H. Robinson \\ Smithsonian Tropical Research Institute \\ P.O. Box 2072, Balboa, Canal Zone, Panama
}

\section{INTRODUCTION}

There are many instances of relationships between insects and spiders that are not simply relationships between predators and prey. Bristowe (1941) cites numerous examples either from his own extensive experience or from a broad review of the diverse literature. Moths have been reported to associate with spiders' webs both as adults and larvae. Thus Pocock (1903) reported a case of commensalism between the gregarious spider Stegodyphus sp. (Erisidae) and the moth Batrachedra stegodyphobius Walsingham. The unnamed species of Stegodyphus from South Africa had small lepidopteran larvae crawling about within the communal web. These fed upon "the carcases of the flies or other insects which, with infinite labour and patience, the spiders hauled up as near their nest as possible. ..." Pocock states that pupation occurred within the nest $(=$ web) and that, after emergence, adult moths moved about the web walking, leaping and fluttering. Reportedly the moths did not get caught in the sticky (cribellate) silk "being gifted apparently, like the spiders themselves, with some safeguard against the stickiness of the threads, which proved so fatal to other insects" (1903: 169). Brach (1977) reports that the webs of Anelosimus studiosus, in Florida are shared by a host of other arthropods including pyralid "webworms." He comments that the relationship between these other arthropods and the Anelosimus is not clear, but that the majority "are found in the periphery of senescent webs and may be physically isolated from contact with colony members by their own silken retreats" (1977:155). Robinson and Robinson (1976:12-16) report on a pyralid moth that, as an adult, rests on

\footnotetext{
*Manuscript received by the editor April 27, 1978
} 
the silk lines of araneid webs. They conclude that the moth gains protection by the association. In this paper I describe the association between larvae of the noctuid moth Neopalthis madates Druce and the colonial spider Anelosimus eximius Simon. In addition, three other instances of associations between lepidopteran larvae and web-building spiders are briefly reported. These involve the araneid Cyrtophora nympha Simon, an undetermined diplurid and an undetermined social theridiid in Papua New Guinea. The relationship between Neopalthis larvae and $A$. eximius is a symbiosis that primarily involves scavenging but may occasionally involve the loss to the spider of usable food resources. Thus the symbiosis is probably commensal for the most part but sometimes (or potentially) deleterious. The terminology of symbioses for such "borderline" cases is in a currently unsatisfactory state.

\section{The NeOPAlthis/ANELOSIMUS Symbiosis}

The nature of the symbiosis can only be understood if some details of the biology of Anelosimus eximius are given. There have been a number of notes on aspects of the biology of this species (e.g., Levi, 1955; Brach, 1975) and it is currently under study at the Smithsonian Tropical Research Institute (by Dr. F. Vollrath). The following notes are based on my own studies and those of Vollrath (pers. comm.). Anelosimus eximius webs are built and occupied by a variable number of spiders, from less than a hundred to at least several thousand. They may persist in one place for many years. One on Barro Colorado Island, Canal Zone, was in the same tree from 1965 to 1971 . Colonies may reach striking proportions, occupying many cubic meters of space. Essentially all webs have a simple basic structure. The lower web consists of a continuous sheet of silk that is concave and often basin-like, being raised at its periphery. Above this and partly attached to it is an aerial snare of threads that are preponderantly oriented more or less perpendicular to the sheet. This is the part that is the effective prey-capture structure. The spiders attack prey within the aerial snare and on the basal sheet. Since the basic web is persistent for long periods, it acquires a litter of plant debris and prey remains. (In captivity the spiders seem to indulge in occasional web-cleaning bouts and carry prey remains to the edge of the web where they are tipped out.) 
I found the first caterpillars in an Anelosimus colony in January 1976. A small colony of less than one hundred individuals was collected from Cerro Galera, Canal Zone, Panama, and taken into the laboratory for behavioral studies. The collection was made by bagging the entire colony on the branch of a tree and then cutting off the branch. This was then set up in a cage. The colony was thus collected intact and complete with all spiders, debris, and inquilines. After some period of observations on the spiders, the caterpillars were seen. There appeared to be several of these; at least two were seen at one time, and eventually four pupae were recovered from the web. When not actively feeding, the caterpillars rested beneath the plant debris in the web or stretched out in sticklike postures. Feeding on insect remains was seen both by day and by night. Movement within the web seemed to be purposively towards prey remains rather than exploratory, but this proved difficult to quantify since the caterpillars had to weave their bodies in and out of the maze-like strands of the snare. In an attempt to investigate the possible cues used by the caterpillars in finding their food, I excised a section of the web away from a spider aggregation and put two caterpillars in this. (Cutting sections of spider web is easy, a hot soldering iron or glowing tip of a lighted cigarette cuts the silk with little pressure.) In this spider-free web I placed a freshly killed tettigoniid (Orthoptera) of about $100 \mathrm{mg}$ weight. The caterpillars made no immediate move towards the katydid, but some hours later both were feeding on it and one was almost inside the body of the dead insect. Figure 1 shows a caterpillar in action. Clearly the caterpillars could feed on an entire insect as well as on exoskeletal fragments. They may well do this in the natural situation. Both caterpillars pupated the morning following this massive meal and this ended the investigation. Caterpillars have been found in other Anelosimus eximius colonies by me and by F. Vollrath (pers. comm.). Vollrath raised Neopalthis madates from his caterpillars and also another moth species that was clearly not a noctuid. This species has not been determined. It is entirely possible that still other species of lepidoptera could be involved in this kind of symbiosis with Anelosimus eximius; this matter is discussed later. Further investigation of the relationship awaits a situation where infested colonies are abundant and can be subjected to traumatic or destructive experimentation. 


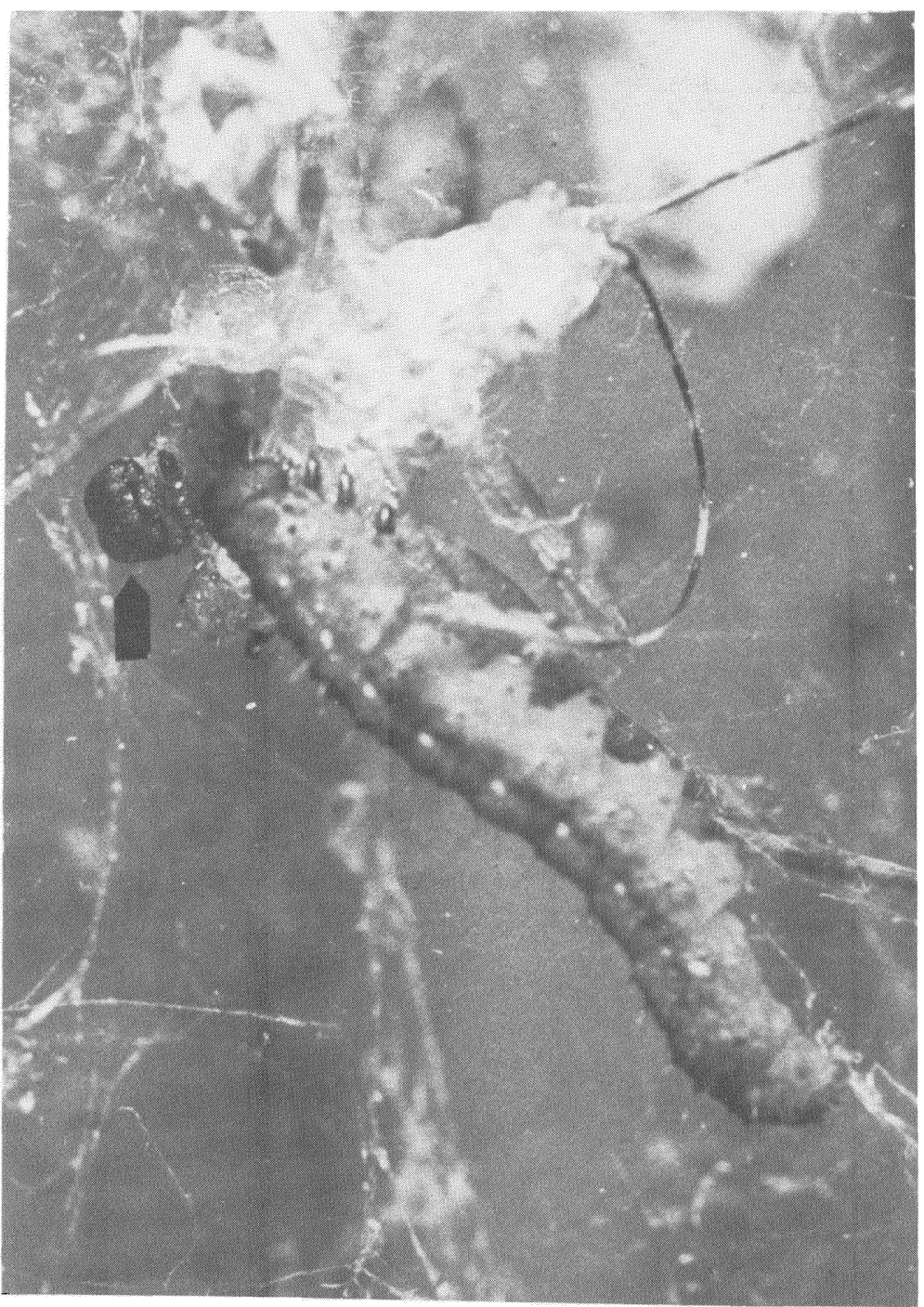

Figure 1. Two larvae of Neopalthis madates feeding on a katydid (see text). One larva is in profile; the other, arrowed, is facing the camera and only the head is visible. 


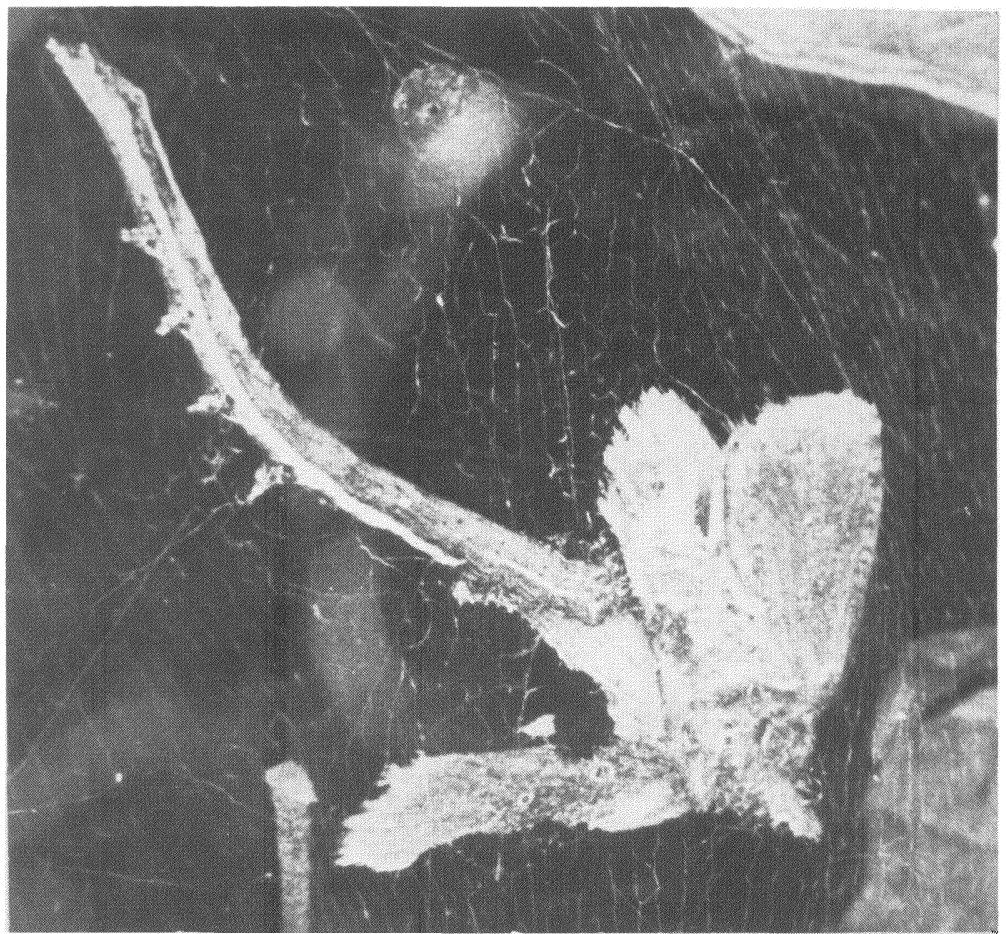

Figure 2. Larva (unidentified) feeding on a moth within the web of Cyrtophora nympha. The characteristic fine mesh of the Cyrtophora web is visible in the background.

\section{OTHER MOTh CATER PILlar/SPIDER SyMbioseS}

The following observations are fragmentary but are worth recording to alert workers in this field to the possibility of widespread symbioses between web-building spiders and lepidopterans. The most excitingly suggestive observation is the discovery, during my brief visit to Wau Ecology Institute, Papua New Guinea, in May 1977, of caterpillars living in colonies of a social theridiid there. The theridiid has not yet been determined and its relationship to the Neotropical Anelosimus eximius is thus unknown. Despite this, it is reasonable to assume that the symbiotic caterpillars represent a case of convergent evolution. I would guess that they were not noctuid caterpillars, but none were collected. 
In Panama a web of the araneid spider Cyrtophora nympha Simon, collected in July 1976 on the Navy Pipeline Road, Gamboa, Canal Zone, contained a single caterpillar moving about in the web in the same way as the larvae in the Anelosimus colonies. This was collected together with the web and the host. The caterpillar is shown in Figure 2. It disappeared without trace.

Finally, F. Vollrath reports (pers. comm.) that he found a caterpillar living in the web of a diplurid and feeding on prey remains; it also apparently fed on the web silk, where it made "dime-sized holes." Neither the diplurid nor the moth have been determined.

\section{Discussion}

So far all the associations between lepidopteran larvae and spiders occur where the hosts build webs that persist for long periods at the same site. This is certainly true of Stegodyphus and Anelosimus colonies and also true of Cyrtophora nympha. The webs of the latter are presumably high investment structures like those of $C$. moluccensis (see Lubin, 1973, 1974); they are solitary and become littered with leaves and debris and often look defunct. An indication of the persistence of C. nympha webs is given by the fact that colonies of Uloborus republicanus often establish themselves in the upper snare (personal observations). In Panama, ground-living diplurids build their sheet webs at one site for long periods and have a wide range of arthropod commensals, kleptoparasites and other symbionts (Vollrath, Kirkendall, pers. comm.). The correlation between persistent webs, or persistent utilization of web sites, and the occurrence of lepidopteran symbionts suggests that the webs of other perennial (or long-term) web-site occupiers should be examined for caterpillar cohabitants. The various gregarious Cyrtophora species are clear candidates for such studies.

Another factor is necessary to provide a niche (within a web) for scavenging cohabitants: clearly there must be an accumulation of prey-remains. If prey-remains were rapidly ejected from the web, there would be no resource for a scavenger to exploit; kleptoparasitism or commensalism would be the only feeding niches available to symbionts. 
The evolution of finely adjusted interspecific relationships must have involved innumerable adaptive steps that are almost inconceivable in their probable complexity. Lepidopteran larvae (and other spiders) may be, as producers and manipulators of silk, somewhat preadapted to evolve symbioses with web-building spiders. Adult butterflies and moths are probably less endangered by sticky spider silk than are most other insects (Eisner, Ettershank and Alsop, 1964) and this could reduce some of the dangers involved in evolving symbioses with spiders. Nonetheless, the caterpillars had to solve two major problems. They had to in some way suppress the predatory responses of the spiders to objects moving on the web and also develop a system of detecting their own food within the web. From my own observations I would conclude that both Stegodyphus sp. and Anelosimus eximius are much less responsive to gently moving objects in their webs than are many orb-weavers. It may have thus been slightly less dangerous for moving caterpillars to invade these webs in the first place, but I strongly suspect that the present immunity to spider attacks depends on something more than the caterpillars "walking softly."

\section{ACKNOWLEDGMENTS}

I am extremely grateful to Dr. E. L. Todd, Systematic Entomology Laboratory, IIBII Institute, U.S. Department of Agriculture, for identifying the moths. My thanks to Dr. F. Vollrath of STRI for access to unpublished observations and for helpful comments.

\section{REFERENCES}

BRACH, V.

1975. The biology of the social spider Anelosimus eximius (Araneae: Theridiidae). Bull. So. Calif. Acad. Sci. 74: 37-41.

1977. Anelosimus studiosus (Araneae: Theridiidae) and the evolution of quasisociality in theridiid spiders. Evolution 31: 154-161.

BRISTOWE, W. S.

1941. The Comity of Spiders. Vol. II. Roy. Soc. London.

Eisner, T., R. Alsop and EtTershank, G.

1964. Adhesiveness of spider silk. Science 146: 1058-1061. LEVI, H. W.

1955. The spider genera Neottiura and Anelosimus in America (Araneae: Theridiidae). Trans. Amer. Microscop. Soc. 75: 407-422. 
LUBIN, Y. D.

1973. Web structure and function: the non-adhesive orb-web of Cyrtophora moluccensis (Doleschall) (Araneae: Araneidae). Forma et Functio 6: 337-338.

1974. Adaptive advantages and the evolution of colony formation in Cyrtophora (Araneae: Araneidae). Zool. J. Linn. Soc. 54: 321-339.

Pocock, R. I.

1903. Notes on the commensalism subsisting between a gregarious spider Stegodyphus sp. and the moth Batrachedra stegodyphobius Wlsm. Ent. Mon. Mag. 39: 167-170.

ROBINSON, M. H. AND B. RoBINSON

1976. The ecology and behavior of Nephila maculata: a supplement. Smithson. Contrib. Zool. 218: 1-22. 

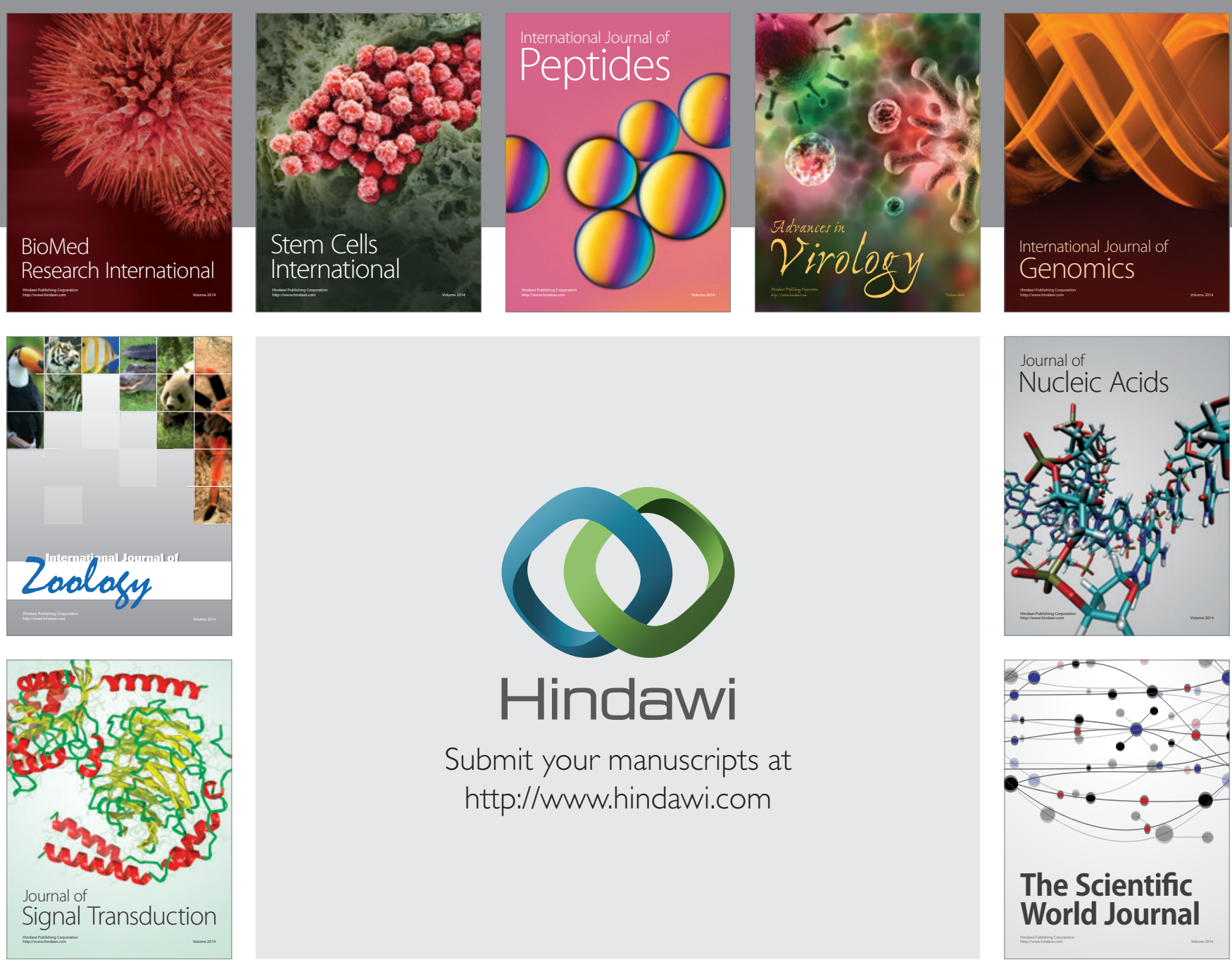

Submit your manuscripts at

http://www.hindawi.com
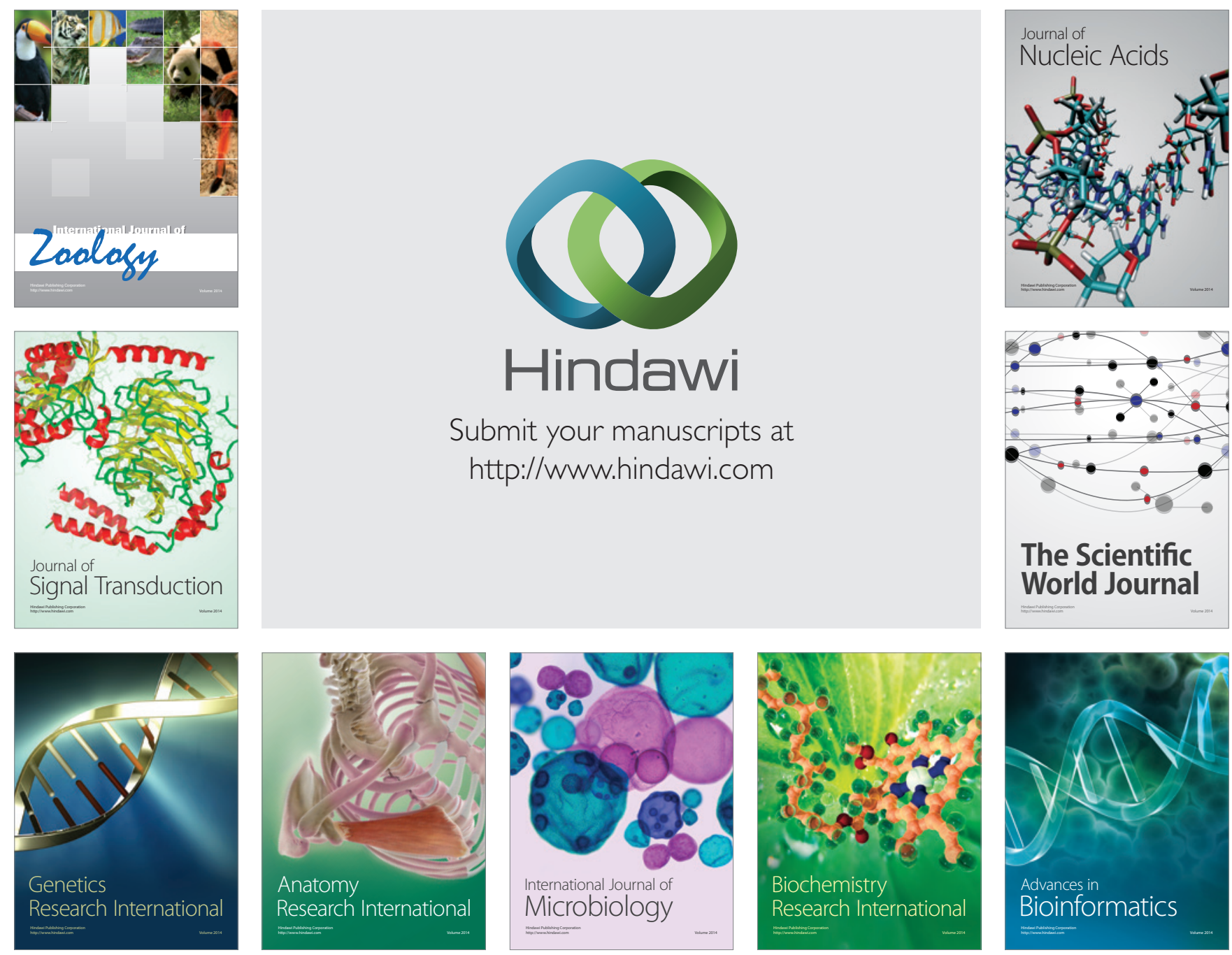

The Scientific World Journal
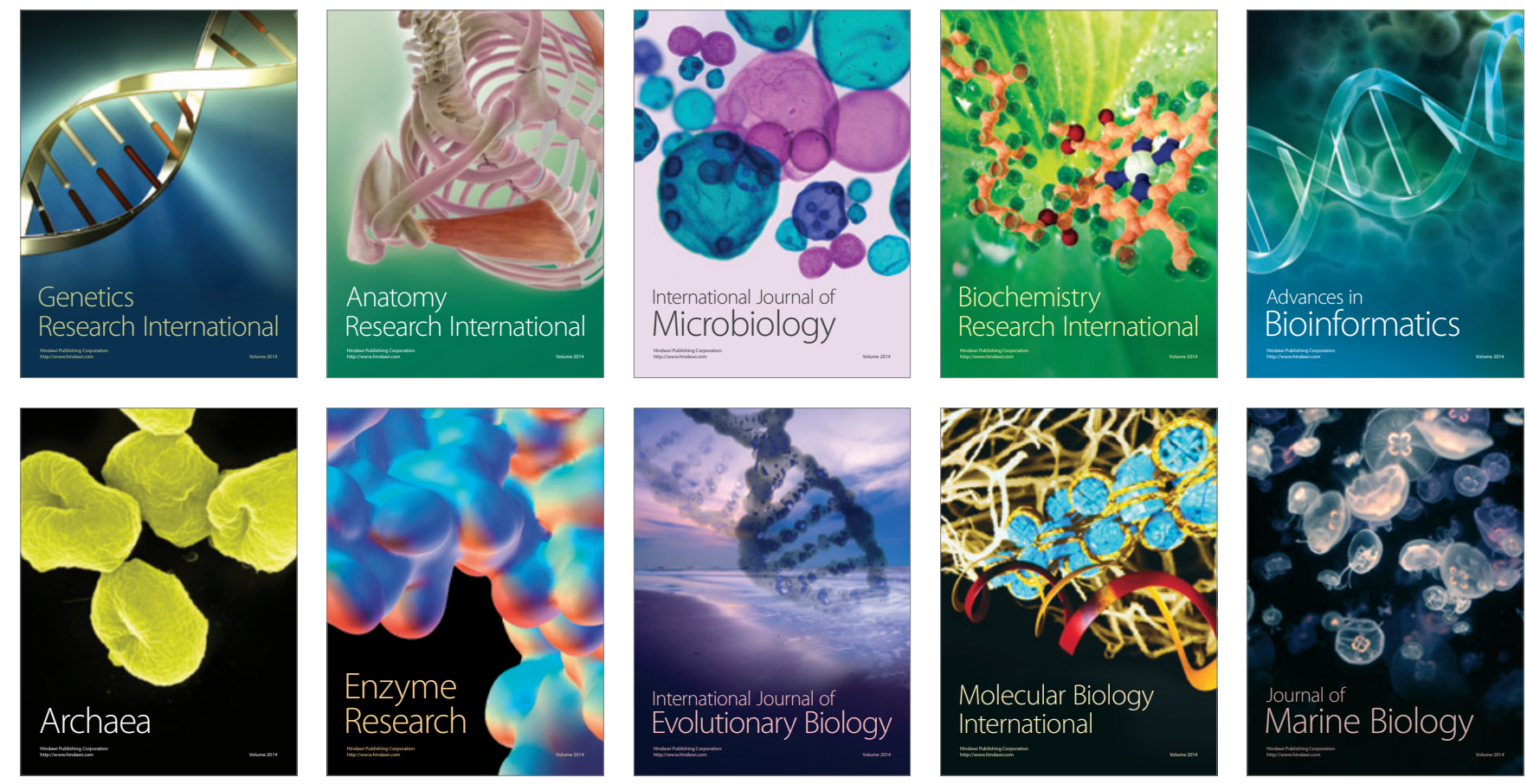